\title{
Analysis of Legal Characteristics in Crime Prevention and Ensuring Social Order - Economic Development of Vietnam
}

\author{
Doan Xuan Hung
}

\author{
People's Police Academy, Hanoi, Vietnam \\ Corresponding author. Email: xuanhung.ppa@gmail.com
}

\begin{abstract}
Currently, along with the strong development of technology, the crime situation is becoming more and more complicated, especially using high technology to commit crimes causing difficulties in the struggle and prevention. Analysis of developments in the situation of crimes and violations of laws on high technology shows that the number of law violations and crimes of using high technology next year is higher than the previous year. Crime of using high technology is getting more and more complicated, with increasing developments in both the number of cases and the nature, extent and consequences. In fact, the number of criminal law violations is relatively high, but the number of prosecutions and prosecutions is very low, because criminals committed on cyberspace, can be in one place but have consequences global, so it is difficult to identify whom to trace and capture, due to cyber and territorial barriers. High-tech crimes and cybersecurity are issues of non-traditional security, which are increasingly popular and impacting, affecting national security. Today, the struggle to prevent crime, ensure social order and safety to stabilize the economic system, not only struggles with the legal system, but also depends on the development of technology and integration cooperation based on international agreements and treaties. Therefore, in order to ensure social safety and at the same time maintain the economic growth rate, especially the economy in the era of technology 4.0, the prevention and fight against hi-tech crimes are a difficult but extremely important task.
\end{abstract}

Keywords: crime, legal, digital technology, Vietnam, socio-economic systems management

\section{INTRODUCTION}

Despite of many efforts, but the situation of crime and law violations in Vietnam is still complicated. State management in many fields is still lacking to keep up with the development of the situation; there are loopholes for crimes and law violations [1-4]. The crime prevention is not effective. The rate of handling news and denunciations against crimes and petitions for prosecution has not reached the set targets (reaching $87.4 \%$ compared to $90 \%$ assigned by the National Assembly); some types of crime are common but the rate of investigation is low. One of the causes is the incomplete system of legal documents in the field of crime prevention and fighting, and many difficulties and problems [5-10]. Although the resources for the prevention and fight against criminals and law violations have been paid attention, they still have not met practical requirements. Professional qualifications and responsibility of some law enforcement officers are limited, even erroneous and negative in the performance of tasks, affecting the effectiveness and efficiency of law enforcement. The paper analyses the evolution of the criminal situation, and the national legal system as well as international legal cooperation to prevent crime in the current context.

\section{COMPLEX PERFORMANCES OF CRIMINAL TYPES IN VIETNAM, ESPECIALLY HIGH-TECH CRIMES, INFRINGING ON THE SOCIAL ECONOMY}

The revolution of science and technology has grown rapidly in a global scale, resulting in the explosion of information technology and telecommunications with the result that the number of people using internet and telecommunication equipment is increasing day by day. Increase rapidly, around the world; almost 2 billion people (equivalent to about $25 \%$ of the global population) use the internet. According to statistics of the Ministry of Information and Communications, in 2019, Vietnam's population will reach approximately 97 million people with the proportion of urban population is $36 \%$. In the same year, users, an increase of $28 \%$ compared 64 million 
Internet to 2017. According to statistics, up to 58 million social network users on mobile devices as of early 2019 , the number this increased to 8 million users over the same period last year. Along with the development of technology, the mid-range and low-end phones are constantly being born, making it easy for many people to own smartphones and access the Internet. Although the population only reached 96.96 million, the number of registered telephone subscribers amounted to 143.3 million [11-16]. This shows that the majority of Vietnamese people have access to smart mobile phones and many people use 2-3 phones at the same time to serve life and work.

Table 1 Vietnam essential headline data you need to understand mobile, internet and social media users (in 2019)

\begin{tabular}{|c|c|c|c|c|}
\hline Total population & Mobile subscriptions & Internet users & $\begin{array}{c}\text { Active social media } \\
\text { users }\end{array}$ & $\begin{array}{c}\text { Mobile social } \\
\text { media users }\end{array}$ \\
\hline 96.96 million & 143.3 million & 64 million & 62 million & 58 million \\
\hline Urbanization: $36 \%$ & vs.Popultation:148\% & Penetration: $66 \%$ & Penetration: $64 \%$ & Penetration: $58 \%$ \\
\hline
\end{tabular}

Information technology and telecommunications have become an area that the subjects focus on exploiting and using for real show criminals. According to the report of the International Criminal Police Organization (INTERPOL), crime using high technology is becoming a major threat in the world. According to the study, it is expected that in just 5 years from 2018 to 2023, the world will suffer more than 146 billion cyber-attacks. The above study only reported and predicted attacks reported. That is the number of undiscovered cyber-attacks is still unknown (as institutions like banking and finance, will never publish information that has been hacked, which will severely affect customers' confidence in the financial services they provide). That number will undoubtedly exceed 146 billion times. Attacks will be increased at a rate of $22.5 \%$ per year. The losses from cyberattacks are increasing. On average, a successful cyberattack cost the company $\$ 3.86$ million (in 2018), for businesses in the U.S., it was $\$ 7.91$ million. Compared to 2017, this number has increased to $6 \%$. It damages businesses in many aspects: from the image of the company, the legal costs of litigation, the public relations as well as the loss of investment opportunities in the present and the future [14].

In Vietnam As of October 2019, there have been more than 1 million cyber-attacks with various forms of attacks, increasing by more than $30 \%$ compared to 2018 . According to the representative of the Information Security Department, cyber-attacks every minute, mobile devices become a common target. Especially banking is one of the regular targets of cyber criminals. Although facing the risk of permanent attack, many organizations are still confused in dealing with network attacks. Only $25 \%$ of agencies are capable of acknowledging cyberattacks, the remaining $75 \%$ of agencies are likely to be attacked without knowing it. Experts stressed that: banks are a unit of interest and need attaching most importance to information security and network security. Banks should invest more for information security.

Cybercriminals in Vietnam not only increase in number and size but also in an increasingly complex manner with many sophisticated tricks, causing enormous damage. In 2019, the damage caused by computer viruses to Vietnamese users amounted to VND 20,892 billion (USD 902 million), far exceeding VND 14,900 billion in 2018. Although there was no particularly serious incident occurred, but the proliferation of computers infected with data encryption and malicious APT attacks was the main cause of these huge damages. The total number of infected computers recorded in 2019 reached 85.2 million, an increase of $3.5 \%$ compared to 2018 [2, 3].

In 2018 and in March 2019, 449 criminal cases were prosecuted, 867 defendants; administrative processing 187 cases related to the field of high-tech use.

The methods and tricks of criminal activities of very sophisticated subjects such as fraud, appropriation of property via social networks, Internet-based voice applications (OTT); perform payment of goods and services via a handheld payment device connected to the network (POS), steal card information or take advantage of online payment services to appropriate property...

Remarkably, there are more and more foreign objects taking advantage of the purpose of tourism entry into Vietnam, those staying at hotels, residential quarters for foreigners, linking with number of Vietnamese subjects to commit crimes.

In addition, the situation of online gambling and soccer betting via the Internet continues to increase significantly nationwide in the form of unsecured gambling (pay later) and mortgage gambling (prepayment) causing great socioeconomic losses to the country.

\section{LEGAL SOLUTIONS IN THE FIGHT AGAINST HI-TECH CRIMES, ESPECIALLY IN THE FIELD OF FINANCIAL PAYMENT IN VIETNAM}

According to a report by Verizon - a US mobile and communications network company surveying compliance with the Payment Card Industry Data Security Standard in 2019,302 organizations in 60 countries around the world, focusing on four areas, including 60 retail organizations, 53 information technology organizations, 32 customer service units and 153 financial service organizations. The survey results show that the level of compliance has changed in a negative direction recently. In 2012, $11.1 \%$ of surveyed organizations met all standards and this rate reached the highest level in 2016 with $55.4 \%$ of organizations, by 2018 , this number fell to $36,7 \%$. This 
shows that meeting the compliance with regulations on security and confidentiality in card payment after 10 years is still a challenge for many units. By region, Asia-Pacific surpasses the Americas, Europe, the Middle East and Africa in terms of compliance with security and security standards. By sector, the financial services and information technology industry achieved better compliance results than the retail and customer service sectors.

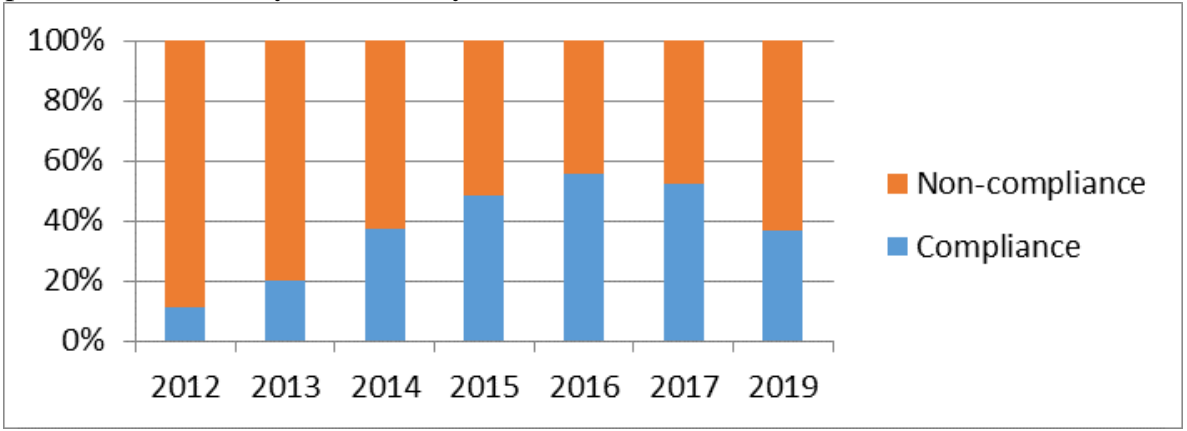

Figure 1 Degree of compliance with security standards, data security

According to a survey by Forrester, a market research company of the United States, for 416 people working in the financial services field in 2018 , about $69 \%$ of mobile phones were both used for work and used at the same time for personal purposes. This makes mobile devices vulnerable to malware or can allow an attacker to access, leak work documents or sensitive data, etc. The growth of mobile payments also raises security concerns.

Recognizing the role and importance of security and confidentiality in electronic payment, card payment in particular and banking activities in general, in recent years, the State Bank of Vietnam has issued many documents aimed at strengthening security, safety and protection of data information, protecting legal rights of customers, such as: Circular 36/2012 / TT-NHNN dated December 28, 2012 on safety regulations operation of automatic trading machines; Circular 47/2014 / TT-NHNN dated December 31, 2014 providing technical requirements for equipment security and safety for bank card payment; Circular 35/2016 / TT-NHNN dated December 29, 2016 providing safety and confidentiality for the provision of Internet banking services; Circular 18/2018 / TT-NHNN dated August 21, 2018, on safety of information technology systems in banking operations; Circular 20/2018 / TTNHNN dated August 30, 2018 regulating the supervision of payment systems, etc. ... In particular, the State Bank of Vietnam has issued a Decision announcing the Ministry of Standards Department of Domestic Chip Cards (Decision 1928 / QD-NHNN dated October 5, 2018), built in the direction of compliance with EMV standards, is recommended by many international card organizations to ensure security, safety and confidentiality in banking card activities, facilitating the increase of features and utilities for cardholders. In addition, the State Bank of Vietnam is also studying to issue a roadmap to apply international standards on security and security such as ISO 27001 for IT systems, PCI DSS standards for card payment systems, new multi-factor security technology replaces outdated insecure security technologies...

Along with that, the State Bank of Vietnam has focused on implementing a number of solutions such as: monitoring the payment systems to ensure safe and effective operation; strengthen the assurance of security and safety in electronic payment; apply payment security standards according to international standards (PCI-DSS, Domestic chip card standards ...); supervise the activities of payment intermediary service providers to ensure the proper operation of regulations; strengthen inspection and examination of safety and confidentiality in e-payment and card payment to assess, detect, early warn risks, handle law violations in e-payment and payment. card payment; regularly coordinate with functional agencies in exchanging information, preventing and combating crimes in card payment and electronic payment activities and announcing new methods and tricks of crimes in payment. In addition, the State Bank of Vietnam also regularly monitors, directs, strengthens the inspection and supervision of card, ATM / POS payment activities and the provision of intermediary payment services; detect and propose timely handling of problems and risks arising, especially public opinion reflected in the mass media, contributing to ensuring card and ATM / POS payment activities. and providing safe, effective payment intermediaries, complying with laws and regulations, as well as contributing to reducing public incidents.

In addition to the achieved results, the author offers a number of legal solutions to the State Bank of Vietnam: it is necessary to continue to improve the legal framework for new products and services; create a legal environment to promote innovation of Fintech organizations, encourage effective and safe Fintech solutions. Studying and applying international standards and practices on information system security and safety to legal documents governing information technology application activities of credit institutions and organizations intermediary payment. Applying credit risk assessment framework in accordance with international practices to improve the quality of inspection and compliance with regulations on security and safety at credit institutions and credit institutions. payment time. Supervise and urge credit institutions to complete the implementation of the Plan to apply security solutions in online payment and bank card payment. 
Accelerate the implementation of the plan to convert magnetic cards to chip cards. To direct credit institutions to consolidate the whole apparatus in charge of information security. Continue to promote activities of the network of information technology incident response networks. Collaborate with functional agencies Ministry of Information and Communications, Ministry of Public Security, Ministry of Defense and organizations providing information technology infrastructure services ... to share information and support activities network safety and security of the banking industry. Continuing to promote communication, raising awareness for bank officials and employees in identifying and minimizing risks of cyber banking activities.

For commercial banks, payment service-providing organizations: solutions for the policy environment and processes are required. Review, finalize and organize the implementation of policies on confidentiality and security Information technology, policies on risk management of information technology comply with the laws of the State and the regulations of the State Bank of Vietnam. Develop a plan to complete the implementation of the tasks specified in the documents of the State Bank of Vietnam. Develop a roadmap for implementing international security standards for information technology systems as well as online payment and card payment services (ISO 27001, PCI / DSS). Closely review the registration process, activate the use of electronic banking services to ensure providing services to the right customers.

\section{COOPERATING IN COMBATING TRANSNATIONAL CRIME WITH COUNTRIES IN THE REGION IN THE CONTEXT OF INTEGRATION, AND THE DEVELOPMENT OF SCIENCE AND TECHNOLOGY}

Vietnam and other countries in the region have built a transnational crime database system, contributing to facilitating the exchange of information quickly, accurately and safely. . Currently, the regional transnational crime database system is accessed through the ASEANAPOL Database System (ADS). The system was started in 1992 and officially put into use in 1998. In 2006, at the initiative of Singapore, ADS was upgraded to an electronic database system (e-ADS). . The 37th ASEANAPOL 2017 Conference in Singapore kicked off the e-ADS e-data system version 2.0 to assist member countries to exchange and share information on prevention and combat of transnational crime quickly. quickly and promptly. In addition, ASEAN has also made continuous efforts in establishing contact points between the member states on transnational crimes and building a database to collect information related to the legislation on prevention and combat. transnational crimes such as national laws, bilateral and multilateral treaties ...
From 2000 to the present, in response to some types of transnational crimes of a complex nature and having a rapidly increasing number in the region, ASEAN leaders have adopted a series of documents relevant legislation to institutionalize a framework of cooperation that contributes to improving the effectiveness of prevention and combat of transnational crime in general and the prevention of terrorism and trafficking in persons in particular.

Vietnam and other countries in the region have built a comprehensive system of regulations on prevention and combat of transnational crimes and consistent with the contents of the relevant international treaties. ASEAN has begun to adopt documents on transnational crime prevention and control since 1976. Among those documents, there are documents with the role of creating an important foundation for the prevention and combat of transnational crime. In ASEAN, such as the Declaration on Transnational Crime in 1997, the Manila Declaration on Prevention and Control of Transnational Crime in 1998. However, there are also documents recognizing specific measures. in order to prevent and combat transnational crimes in member countries, such as the 1996 Transnational Crime Action Plan, the Action Plan for the implementation of the 2002 Transnational Crime Action Plan. specific types of transnational crimes, especially those of a complex nature and tending to increase in the region such as illegal drug trafficking, terrorism and human trafficking, especially trafficking in women and children, ASEAN member states agreed to sign treaties. In order to meet the obligations of States Parties, the obligations of related parties shall be enshrined in those treaties. A number of recent signed treaties are ASEAN Convention on Terrorism Prevention 2007, ASEAN Convention on the Prevention and Fight against Trafficking in Persons, Especially Women and Children, 2015. In general, transnational crime provisions in ASEAN documents are compatible with the content of multilateral international treaties on transnational crimes. Specifically: United Nations Convention against Transnational Organized Crime in 2000; Protocol on preventing, preventing and punishing human trafficking, especially trafficking in women and children; Supplementing the 2000 Transnational Organized Crime Convention.

Currently, ASEAN documents list 11 types of crimes classified as transnational crimes, defining obligations of member states to criminalize transnational crimes into the domestic legal system. In addition, contents related to criminal justice assistance activities among ASEAN member countries such as scope of assistance, content of assistance, assistance bodies, order of assistance, etc. are recorded at ASEAN Criminal Justice Assistance Agreement 2004.

However, these documents have different legal validity, in which, most of them are political documents expressed in the form of Declaration, Action Plan, Action Program and the Master Plan again is not binding. This reduces the effectiveness of the regional transnational crime prevention and control commitments. In addition, 
measures to prevent and combat transnational crimes recorded in the documents (legal and political documents) are considered as measures showing a soft mechanism of cooperation such as exchanging information and best practices, establishing liaison networks between specialized agencies and cooperating on a reciprocal basis ... Can explain the phenomenon The above comes from one of ASEAN's specific principles that clearly shows "The ASEAN Way" which is the principle of noninterference in each other's internal affairs. Therefore, the effective implementation of commitments on ASEAN transnational crime prevention and control is actually relatively limited. In addition, the obligations of member states to criminalize transnational crimes in their domestic laws are still inconsistent.

Collaborating against transnational crimes with dialogue parties and international organizations. Through ASEAN, Vietnam has strengthened its network of cross-border crime cooperation and cooperation with dialogue countries and International organizations. The result of cooperation in this area is the series of joint declarations on counterterrorism between ASEAN and Japan, Korea, India, Russia, New Zealand, Australia, Canada, United States, Pakistan and A joint statement between ASEAN and China on cooperation in non-traditional security areas ... was signed. In addition, ASEAN strengthens the informal dialogue between senior ASEAN officials and the dialogue parties, and at the same time calls for the dialogue partners to support ASEAN in the implementation of action programs on defense, fight transnational crime.

In the current digital technology context, in order to improve cooperation efficiency, the following solutions need to be synchronized:

Firstly, it is necessary to enhance information exchange activities through existing communication channels such as databases e-ADS, the International Crime Database System of the International Criminal Police Organization (INTERPOL), and the establishment of new, more effective communication channels between agencies specialized cooperation of member states.

Secondly, upgrading the legal binding of some existing documents and increasing the number of regional international treaties on the prevention of transnational crimes; there is a need to further tighten mechanisms to ensure the implementation of member states 'commitments instead of existing mechanisms such as coordination, review or reporting of Member States' enforcement activities to relevant agencies. ASEAN.

Thirdly, strengthening the role of transnational crime prevention and control institutions through coordination with other relevant ASEAN agencies; establish a permanent agency for transnational crime prevention and control to contribute to support the agencies operating according to the ASEAN meeting in the time without the meeting to promptly respond to the situation important and important situations for preventing and combating transnational crimes.

\section{CONCLUSION}

In 2020, based on forecasting the situation of crimes and law violations will continue to be complicated, increasing pressure, in order to better perform the work of preventing and combating crimes and law violations, must have solutions, key tasks. Promote the development and improvement of legal institutions, mechanisms and policies related to crime prevention and fight, violations of law, and solving difficulties and obstacles, contributing to improving work efficiency crime prevention and law violation in Vietnam.

\section{REFERENCES}

[1] Akama, J. S. Tourism development in Kenya: Problems and policy alternatives. Progress in Tourism and Hospitality Research 1997 3(2): 95-105.

[2] Bennett, O., Roe, D. and Ashley, C. Sustainable Tourism and Poverty Elimination Study: A Report to the Department for International Development, London: DFID 1999.

[3] Mbaiwa, J. E. The problems and prospects of sustainable tourism development in the Okavango Delta, Botswana. Journal of Sustainable Tourism 2005 13(3): 203-227.

[4] Rodricks, I., ed. 2001. A Route Out of Poverty, Bangkok: United Nations Economic and Social Commission for Asia and Pacific (ESCAP).

[5] Reports of the General Department of Police, Crime Prevention - Vietnam Ministry of Public Security.

[6] Circular 35/2016 / TT-NHNN dated December 29, 2016 providing safety and confidentiality for the provision of Internet banking services.

[7] Circular 18/2018 / TT-NHNN dated August 21, 2018 , on safety of information technology systems in banking operations.

[8] Vietnam Statistical Yearbook through the years and the Socio-Economic Development Report of the years on the website of the Government and the Ministry of Planning and Investment.

[9] Socio-economic development reports for years on the Government's website and the Ministry of Planning and Investment.

[10] General Statistics Office: Statistical Yearbook 2018, Statistical Publishing House, Hanoi, 2019

[11] Mazyrin, Vladimir M. Economic Modernization in Vietnam from Industrialization to Innovation Stage. 
VNU Journal of Science: Economics and Business, [S.1.], v. 29, n. 2, june 2013. ISSN 2588-1108.

[12] ADB (2007), "Agricultural land conversion for industrial and commercial use: Competing interests of the poor", In ADB (Ed.), Markets and Development

Bulletin (pp. 85-93), Hanoi, Vietnam: Asian Developmen Bank.

[13] Socio-economic development reports for years on the Government's website and the Ministry of Planning and Investment.

[14] Kenichi Ohno. Avoiding the Middle-Income Trap: Renovating Industrial Policy Formulation in Vietnam. ASEAN Economic Bulletin. Vol. 26, No. 1, Vietnam: Coping with Domestic and External Challenges (April 2009), pp. 25-43

[15] Tran K D. Vietnamese Schooling in Transition: Industrialization and Modernization. CICE Hiroshima University, Journal of International Cooperation in Education, Vol.11 No.1 (2008) pp.85 96

[16] C. Y. Ng, Nick J. Freeman, Frank C. H. Huynh. State-owned Enterprise Reform in Vietnam: Lessons from Asia. Institute of Southeast Asian Studies, Singapore. 1996. 170p. 